\author{
Bishimbayeva N.K. ${ }^{*}$, Sartbayeva I.A. ${ }^{1}$, Murtazina A.S. ${ }^{1}$, Gunter E.A. ${ }^{2}$ \\ ${ }^{1}$ The Institute of Plant Biology and Biotechnology, Almaty, Kazakhstan \\ ${ }^{2}$ The Institute of Physiology of Komi, Syktyvkar, Russia \\ *e-mail: gen_jan@mail.ru
}

\title{
Chemical composition of polysaccharides from wheat cell culture
}

\begin{abstract}
Polysaccharides were extracted from wheat suspension culture and cultivated cells. Gaz-liquid chromatography of wheat suspension culture allowed identifying the composition of polysaccharides that were found to contain arabinose, xylose, galactose, glucose, and a little amount of mannose and rhamnose. In dried cultivated cells the polysaccharide structure consisted mainly from arabinose, xylose, and galactose. It was found that the percentage of the amount of monosaccharides was positively correlated with the concentration of 2,4-D at the suspension media.
\end{abstract}

Key words: plant polysaccharides, chemical composition, wheat cell culture

\section{Introduction}

Plant polysaccharides are famous for their important technical and physiologic traits. Currently, polysaccharides attract researchers with their high biological activity in regulating the growth, development and protection processes and are of a great interest in the search for and the production of new biologically active compounds $[1,2,3]$.

Like a native plant, cell culture is capable for synthesis of a wide range of polysaccharides such as pectin, arabinogalactan, galactans, arabinans, xyloglucans, etc. $[4,5]$. Studies of plant polysaccharides conducted mainly on various organs of the intact plants [6]. The polysaccharides derived from cell cultures of plant organs and plant cell lines, are much less become the objects of studies and are of a particular research interest.

Plant cell cultures serves as a convenient model system for studying the structure and biosynthesis of polysaccharides. Cell cultures have several advantages over the traditional raw materials: no organismic control, absence of dependency from the weather conditions, the ability to influence trophic, hormonal and physical factors, the possibility of streamlining and standardizing processes, the homogeneity of the system, the ability to identify the genes responsible for the synthesis of biologically active substances [7].

Our earlier investigations have shown that the ability to maintain embryogenic potential of the longterm cultivated embryogenic tissues of wheat and barley accompanied by the appearance of extracellular polysaccharides [8]. In addition, we have determined high level of biological activity of polysaccharides obtained from embryogenic suspension culture [9]. The purpose of this study is to determine chemical composition of polysaccharides obtained from wheat suspension culture and dried cultivated cells.

\section{Materials and methods}

The study object was an embryogenic suspension cell culture of wheat (Triticum aestivum). Suspension culture was grown in the Murashige and Scoog [10] liquid nutritious media with the addition of 1.0 and $5.0 \mathrm{mg} / 1$ of 2,4-D. The suspension liquid was filtered from suspension culture and was evaporated on rotary evaporator under $45-50^{\circ} \mathrm{C}$. Extracellular polysaccharides from suspension liquid were extracted according to Gunter [11]. Polysaccharides inside the cells were extracted by water (I fraction) and by solution of ammonium oxalate (II fraction) from suspension cells. After that, solutions containing polysaccharides were evaporated and dried. The percentage output of monosaccharide composition was estimated on and compared with their initial dry biomass.

Protein composition in polysaccharide fractions was estimated by Louri methodology [12]. Overall polysaccharides presence and quantity was determined by phenol - sulfuric acid method by Dubious [13]. Spectrometric investigation was undertaken on the Ultraspec 3000 equipment. Monomers composition of polysaccharides was detected by Hewlett- 
Packard 4890A gaz-liquid chromatography with plasma-ionization detector.

\section{Results and their discussion}

Polysaccharides were extracted from wheat liquid suspensions and wheat cells. Extracellular polysaccharide containing liquid suspension was purified from low molecular weight compounds and other unnecessary compounds by dialysis. Obtained polysac- charide samples were tested by phenol-sulfuric acid method [13].

Monosaccharide composition of extracellular polysaccharides from wheat liquid suspension was detected by gas liquid chromatography (GLC). GLC allowed to identify that the quantity of monosaccharaides obtained from media with $5.0 \mathrm{mg} / 1$ 2,4-D is considerably higher than those that growth on media with $1.0 \mathrm{mg} / 1$ 2,4-D (Figure $1 \mathrm{a}, \mathrm{b}$ ). However, the chromatographic profiles of both concentrations were similar.

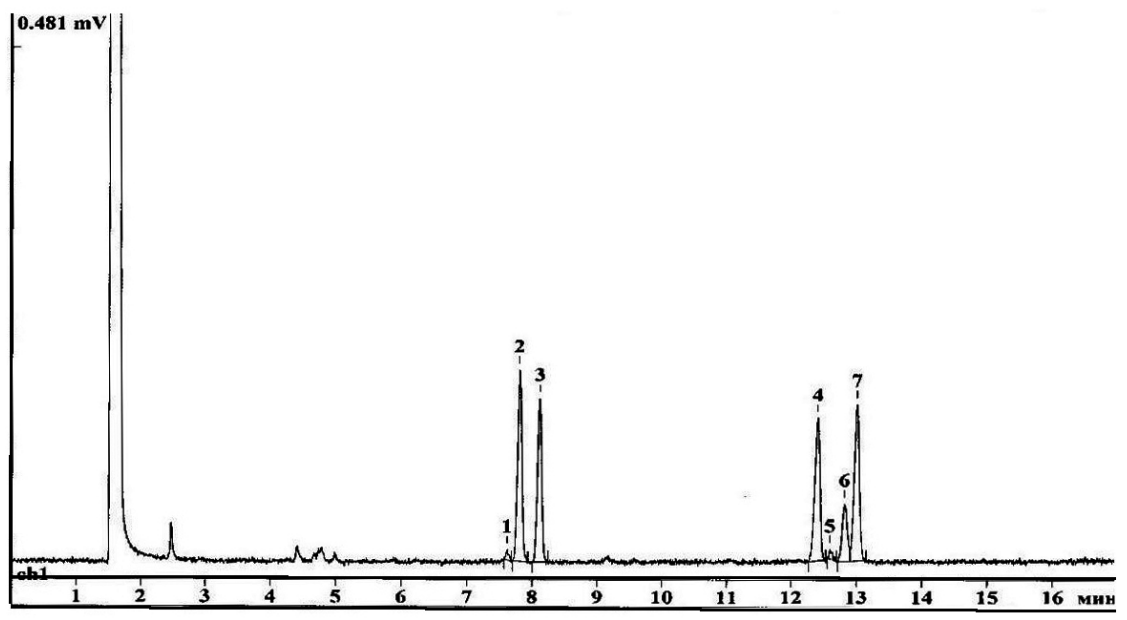

1 - rhamnose, 2 - arabinose, 3 - xylose, 4 - inosit, 5 - mannose, 6 -glucose, 7 - galactose

Figure 1 (a) - Analysis of monosaccharide composition of polysaccharides from $1,0 \mathrm{mg} / \mathrm{ml}$ 2, 4 D media, using GLC

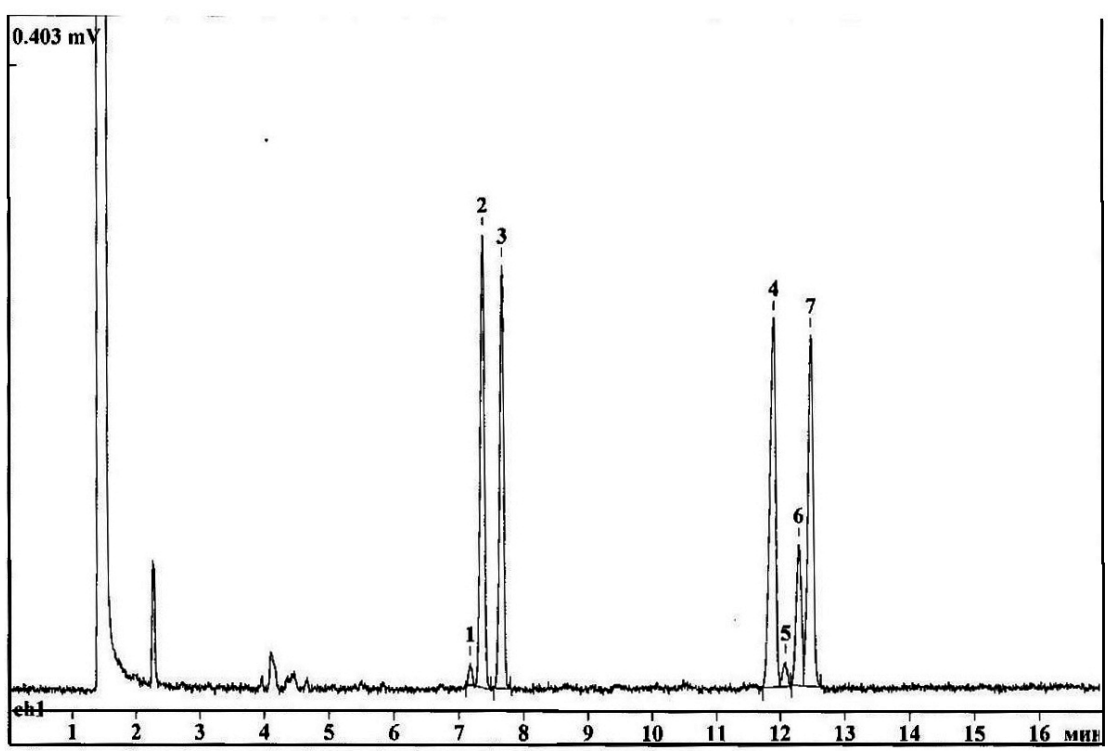

1 - rhamnose, 2 - arabinose, 3 -xylose, 4 - inosit, 5 - mannose, 6 - glucose, 7 - galactose

Figure 1 (b) - Analysis of monosaccharide composition of polysaccharides from $5.0 \mathrm{mg} / \mathrm{ml}$ 2,4 D media, using GLC 
Analysis of chromatographic profile for monosaccharide composition of polysaccharides obtained from wheat liquid suspension revealed that the quantity of arabinose, xylose, galactose, and glucose monosaccharaides were considerably higher than the quantity of ramnose and mannose. Figure 2 presents percentage of each monosaccharide in polysaccharides obtained from suspension culture.
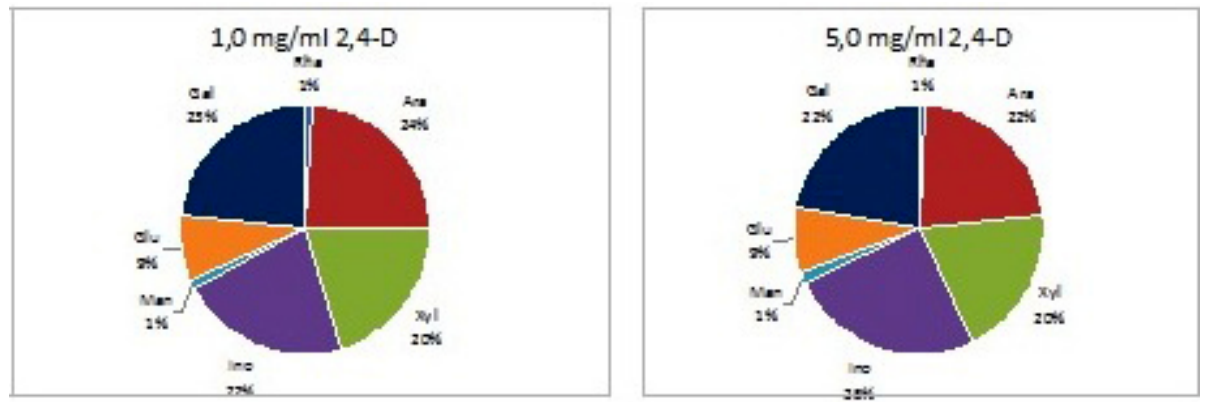

Figure 2 - Percentage ratio of monosaccharides in polysaccharides obtained from suspension culture grown on different 2,4 D concentrations

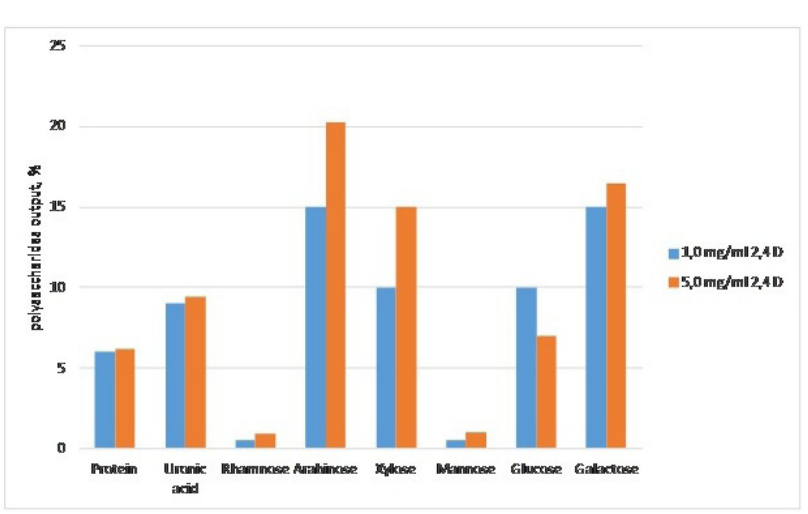

1 - proteins, 2 - uronic acids, 3 - ramnose, 4 - arabinose, 5 -xylose, 6 - mannose, 7 - glucose, 8 - galactose

Figure 3 - Monosaccharide composition of extracellular polysaccharides from wheat liquid suspension (\%)

It was determined that the quantity of all monosaccharaides of extracellular polysaccharides obtained from suspension culture grown on Murashige and Schoog media containing $5.0 \mathrm{mg} / 1$ 2,4-D is considerably higher than those grown on media with 1,0mg/12,4-D, except glucose. There were no significant difference in the quantity of uronic acid $(9.16 \%$, $9.64 \%)$ and proteins $(5.85 \%, 6.08 \%)$ between polysaccharide samples of $1.0 \mathrm{mg} / 1$ and $5.0 \mathrm{mg} / 1$ 2,4-D concentrations (Figure 3 ).

In order to characterize biosynthetical activity of cultivated cells, wheat cell suspension culture grown on Murashige and Skoog media was filtered and two fractions of polysaccharides were obtained. The first fraction (I fraction) was obtained from dried cells water exctract, whilst the second fraction (II fraction) was extracted by the solution of ammonium oxalate.

The analysis of the first fraction of cell polysaccharides revealed the increase of polysaccharides, protein, and uronic acid quantity with the escalation of 2,4-D enzyme concentration in culture media (Table 1). The quantity of the same compounds in the second fraction was found to have a similar dependence pattern with 2,4-D concentration increase, especially significant increase was found in uronic acid percentage (Table 1).

Table 1 - The percentage of polysaccharides, protein and uronic acid in extract from dried wheat cells

\begin{tabular}{|c|c|c|c|c|}
\hline \multirow{2}{*}{ Fractions } & $\begin{array}{c}\text { 2,4-D con- } \\
\text { centration in } \\
\text { media, mg/1 }\end{array}$ & $\begin{array}{c}\text { Polysac- } \\
\text { charides, } \%\end{array}$ & Protein, \% & $\begin{array}{c}\text { Uronic } \\
\text { acid, } \%\end{array}$ \\
\hline \multirow{2}{*}{ I } & 1.0 & 0.93 & 4.06 & 14.72 \\
\cline { 2 - 5 } & 5.0 & 1.95 & 5.98 & 17.00 \\
\cline { 2 - 5 } & 1.0 & 0.59 & 5.02 & 27.77 \\
\hline \multirow{2}{*}{ II } & 5.0 & 0.77 & 6.45 & 66.40 \\
\hline
\end{tabular}

Analysis of monosaccharide composition the I and II fractions obtained from wheat dried cultivated cells revealed that the quantity of arabinose, xylose, galactose were considerably higher rather than the quantity of neutral monosaccharaides ramnose and mannose (Figure 4). It is important to point out that 
the percentage of monosaccharides were higher in fraction I, which means that extraction method for the first fraction was more effective than the second one for both 2,4 D concentrations. Also, it was determined that, similar to polysaccharides from suspension culture, percentage of monosaccharides from dried callus cells showed the same dependency pat- tern from the 2,4 D concentration increase. In other words, the percentage of monosaccharides increases with the escalation of 2,4-D in media. Thus, the quantity of arabinose, xylose and galactose (except galactose fraction I) is two times higher in polysaccharides from callus cells grown on $5.0 \mathrm{mg} / \mathrm{ml} 2,4 \mathrm{D}$, compared to $1.0 \mathrm{mg} / \mathrm{ml} \mathrm{2,4} \mathrm{D} \mathrm{(Figure} \mathrm{4).}$

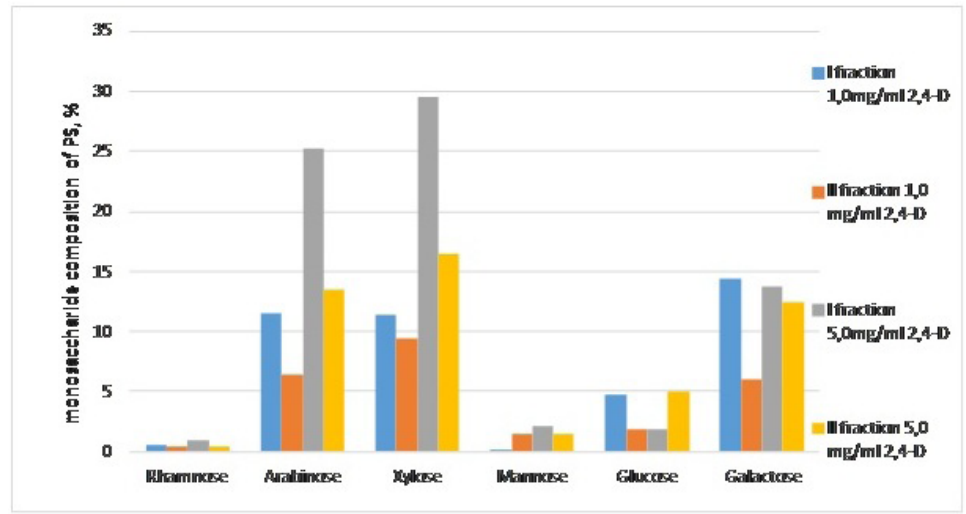

Figure 4 - Monosaccharide composition of extracellular polysaccharides from wheat dried cultivated cells

The study has shown that extracellular polysaccharides obtained from wheat liquid suspension culture consist of arabinogalactans, arabinoxylans, and xyloglucans. Polysaccharides extracted from wheat dried cultivated cells were found to contain of arabinogalactans and arabinoxylans. These findings correspond to earlier scientific investigation results on arabinogalactans [14] and xyloglucans [15] obtained from plant culturing in vitro described in literature. In addition, wide range of data in literature suggests that arabinogalactans and xyloglucans are capable to provide high biological activity. Considering earlier positive results of bioassays conducted in our laboratory [9], we assume that the high biological activity of substances obtained and extracted from liquid suspensions and dried cultivated cells explained by presence of these polysaccharides. Therefore, investigation of high biological activity of identified polysaccharides is the issue for our future research.

\section{References}

1. Waggner H., Stuppner H., Schafer W., Zenk M. Immunologically active polysaccharides of Echinacea cell culture // Phytochemistry, 1988. Vol. 27. - P. 119-126.

2. Roesler J., Emmensuffer A., Steinmiller C., Luetting B., Wagner H., Lohman-Matthes M.L. Ap- plication of purified polysaccharides from cell cultures of the plant Echinacea purpurea to test subjects mediated activation of the phagocyte system // Int.J.Immunopharmac, 1991. - Vol. 13. - P. 931-941.

3. Ovodov U.S. Polysaccharides of flowering plants: structure and physiological activity // Bioorganic chemistry, 1998. - Vol. 24. - P. 483-501.

4. Goubet F., Morgan C., Synthesis of Cell Wall Galactans from Flex (Linumusitatassimum L.) Suspension-cultures Cells // Plant and Cell Physiology, 1994. - Vol. 35. - No. 5. - P. 729-727.

5. Gunter E.A., Popeyko O.V., Ovodov Yu.S., Modification of polysaccharides from callus culture of Silene vulgaris M. using carbohydrases in vitro // Biochemistry, 2007. - Vol. 72. - No. 9. - P. 10081015.

6. Olennikov D.N., Kashenko N.I. Polysaccharides. Modern state of research: experimentalscientific study // Chemistry of natural raw materials. 2014. - No. 1. - P. 5-26.

7. Gunter E.A. Pectin compounds of plant cellular cultures. Thesis. Syktyvkar, 2012.

8. Bishimbayeva N.K., Denebayeva M.G., Amirova A.K., Rakhimova E.V. Features of histological structure of friable embryogenic callus of barley // Proceedings of the National Academy of Sciences of the Republic of Kazakhstan: Series biological and medical, 2001. - No. 1-2. - P. 7-14. 
9. Bishimbayeva N.K., Amirov A.K., Murtazina A.S., McDougall G.J., Rakhimbayev I.R. Biological activity of extracellular polysaccharides in suspension culture cells of wheat // Physiological, biochemical and genetic and breeding plant research in Kazakhstan / Collection of articles, 2010 - P. 103-111.

10. Bishimbaeyva N.K. Cytophysiologic basics of long-term regeneration biotechnology in tissue culture of cereals / Synopsis for the doctor of biological sciences defense, Almaty, 2007, 38 p.

11. Murashige T., Scoog F.A. revised medium for rapid growth and bioassays with tobacco tissue cultures // Physiol.Plant, 1962. Vol. 13. - P. 473-497.

12. Gunter E.A. Non-traditional plant's cell cultures as polysaccharides producers // Chemistry and computer modeling. Butler messages, 2001. - Vol. 5. - P. 11-12.
13. Lowry O.H., Rosebrough N.J., Farr A.L., Randall R.J. Protein measurement with the folin phenol reagent // J. Biol. Chem., 1951. - Vol. 193. P. 265-275.

14. Dubious M., Gilles K. A., Hamilton J.K., Rebers P.A., Smith F. Colorimetric method for determination of sugars and related substances // Anal. Chem., 1956. - Vol. 28. - P. 350-356.

15. Arjon J. van Hengel, Zewdie Tadesse, Peter Immerzeel, Henk Schols, Ab van Kammen, Sacco C. de Vries. N-acetylglucoseamine and GlucosamineContaining Arabinogalactan proteins Control Somatic Embryogenesis // Plant Physiol., 2001. - Vol. 125. - P. 1880-1890.

16. McDougall G. J., Fry S.C. Structure-activity relationships for xyloglucan oligosaccharides with antiauxin activity // Plant Physiol, 1989. - Vol. 89. P. 883 